\title{
The isolation of stimulus-reinforcer associations established with multiple schedules
}

\author{
STANLEY J. WEISS \\ The American University, Washington, D.C. 20016
}

\begin{abstract}
Multiple schedules established stimulus-reinforcer $\left(\mathrm{S}-\mathrm{S}^{\mathrm{R}}\right)$ associations on baselines in which equal response rates and patterning were maintained in all components. Subsequently, stimuli associated with an increase in reinforcement but no change in ongoing response rate were compounded. For one experimental group, free-operant avoidance (FOA) was programmed in tone and in light while variable-interval (VI) food reinforcement was effective in their simultaneous absence $(\overline{\mathrm{T}}+\overline{\mathrm{L}})$. The opposite stimulus-schedule combinations were programmed for the other. Both groups remained in their VI components $85 \%$ of the session on schedule preference tests, and on a stimulus compounding test emitted approximately 1.5 times as many responses to tone-plus-light $(T+L)$ as to tone or light alone. This is the first report of additive summation to combined discriminative stimuli associated with only an increase in reinforcement. Nondifferentially trained controls who had the same contingency effective in tone, light, and $\overline{\mathrm{T}}+\overline{\mathrm{L}}-\mathrm{VI}$ or FOA - showed neither preference among schedule components or summation during stimulus compounding, indicating that nonassociative stimulus factors made no contribution to either resultant in the experimental animals. Evidence supporting an algebraic combination of response and reinforcement associations is presented, and functional similarities between transfer-of-control studies and the stimulus compounding tests of the experimental groups in the present experiment are discussed.
\end{abstract}

When an organism's operant response rate is under discriminative stimulus $\left(\mathrm{S}^{\mathrm{D}}\right)$ control a stimulusresponse-reinforcer $\left(S-R-S^{R}\right)$ sequence is usually established. Within this framework, two types of association to the $S^{D}$ may be identified, the stimulusresponse (S-R) association established through the response-reinforcer contingency and the stimulusreinforcer $\left(S-S^{R}\right)$ association. The contribution of each type of association to stimulus control is often ambiguous, because on most multicomponent freeoperant baselines response rate and reinforcement rate are highly correlated. As an example, consider a three-component multiple schedule where responding is maintained to a tone and a light by reinforcement while in the absence of both tone and light $(\bar{T}+\bar{L})$ responding is eliminated through nonreinforcement. Here, the tone and the light (1) will come to be discriminative for an increase in response rate, the $S-R$ association, and (2) will signal an increase in reinforcement frequency, the $S-S^{R}$ asociation. This confounding of $\mathrm{S}-\mathrm{R}$ and $\mathrm{S}-\mathrm{S}^{\mathrm{R}}$ associations complicates causal analysis when behaviors may be ex-

\footnotetext{
This research was supported by Grant $\mathrm{MH}-16853$ from the National Institute of Mental Health, United States Public Health Service. It was presented at the 1975 convention of the Psychonomic Society in Denver, Colorado. The author appreciates the assistance he received in conducting this experiment from Shin-Yuan Tsai and Shelley Hurwitz. Reprints may be obtained from the author, Department of Psychology. The American University, Washington, D.C. 20016.
}

plained by attending exclusively to either type of association. This is exemplified by the problems encountered in interpreting the results of a stimulus compounding test administered after training on the three-component multiple schedule described above.

On this stimulus-compounding test, tone-plus-light $(\mathrm{T}+\mathrm{L})$ will control more responding than tone or light presented alone, a phenomenon called additive summation (Miller \& Ackley, 1970; Weiss, 1964, 1971; Wolf, 1963). If the S-R, or habit, association is emphasized in this instance one would postulate that more responding is expected in the presence of two stimuli discriminative for responding $(T+L)$ than to one (tone or light). On the other hand, one could postulate that two reinforcement-associated stimuli should maintain more responding than one, a motivational explanation emphasizing the $\mathrm{S}-\mathrm{S}^{\mathrm{R}}$ association (Mowrer, 1947; Rescorla \& Solomon, 1967; Trapold \& Overmier, 1972).

It has been established that differential S-R associations to tone and light were themselves sufficient for summation to $\mathrm{T}+\mathrm{L}$ (Weiss, 1971; Weiss \& Van Ost, 1974). Here, tone and light each controlled higher response rates than, but reinforcement density equivalent to, that in the $\overline{\mathrm{T}}+\overline{\mathrm{L}}$. However, the magnitude of this summative result was influenced by the $S-S^{R}$ association conditioned to tone and to light by reinforcement differences between these stimulus conditions and $\overline{\mathrm{T}}+\overline{\mathrm{L}}$ (Weiss, 1971; Weiss \& Van Ost, 1974). Nevertheless, in all instances of summation, each of the stimuli compounded was 
itself discriminative for an increase in the operant response measured, i.e., an $S-R$ association was present. Therefore, whether the $S-S^{R}$ associations acquired on these baselines are in themselves adequate for free-operant summation has not been determined. To test this possibility, baselines were employed in the current experiment on which differential S-R associations were not established to tone or light while $S-S^{R}$ associations were.

\section{Design}

The training baselines for the experimental groups in the current study were so chosen that (1) equal response rates and comparable response patterning were obtained in tone, light, and $\bar{T}+\overline{\mathrm{L}}$ schedule components, while (2) tone and light were each associated with a clear increase in the reinforcer (incentive) maintaining responding in their presence.

It was extremely difficult to accomplish both objectives when the same class of reinforcer maintained responding in all schedule components. However, both criteria could be met if different classes of reinforcement (positive or negative) were programmed in the several $S^{D_{S}}$. Consider the instance where food maintains responding in tone and in light while shock avoidance maintains responding in $\overline{\mathrm{T}}+\overline{\mathrm{L}}$. An avoidance contingency should generate little, if any, positive incentive. Therefore, there would be an increase in positive incentive in tone and light conditions relative to $\bar{T}+\overline{\mathrm{L}}$. Then, on a stimulus compounding test, $\mathrm{T}+\mathrm{L}$ would contain two stimuli associated with an incentive increase while tone or light would each contain only one. Likewise, when responding is maintained by avoidance in tone and in light, while it is maintained by food in $\bar{T}+\overline{\mathrm{L}}$, tone and light should again each be associated with an incentive increase, albeit negative.

The experimental design presented in the two-bytwo matrix of Table 1 also includes two nondifferentially trained control groups. These groups had the same contingency operating in tone, light, and $\overline{\mathrm{T}}+\overline{\mathrm{L}}$ during training. With this arrangement, neither $S-R$ or $S-S^{R}$ associations should here be formed to tone or light, making these stimuli noninformational (cf. Rescorla, 1972). Therefore, summative effects during compounding that are associative in nature would not be predicted. These control groups do establish, however, a unique referent for possible nonassociative stimulus factors that might be operating when stimuli are presented simultaneously in situations where responding is maintained by positive or negative reinforcement.

\section{METHOD}

Subjects

Thirty-two male Long-Evans hooded rats served as subjects.
Training commenced after they had been deprived to approximately $80 \%$ of their free-feeding weights which ranged from 350 to $435 \mathrm{~g}$. They were housed in individual cages where water was continuously available. Food acquired during training was supplemented by Tekland rat diet ration to maintain the rats at their predetermined weights.

\section{Apparatus}

The three similar operant training chambers measured $20 \mathrm{~cm}$ high, $21 \mathrm{~cm}$ long, and $17.5 \mathrm{~cm}$ wide. The front and rear chamber walls were constructed of aluminum. The side walls and ceiling were $0.6 \mathrm{~cm}$ white translucent and clear plastic, respectively. The ceiling was vented with $0.6-\mathrm{cm}$-diam holes. The chamber floor was composed of $0.3-\mathrm{cm}$-diam stainless steel rods spaced apart $1.3 \mathrm{~cm}$ between centers. A Gerbrands microswitch lever was located on the right side of the front wall, $6.9 \mathrm{~cm}$ above the floor. During preference test sessions, a $11.1-\mathrm{cm}-\mathrm{long}, 0.6-\mathrm{cm}$-wide chain, attached to a microswitch mounted on the top of the chamber, hung from the midline of the ceiling $13.4 \mathrm{~cm}$ from the front wall. A force equivalent to $15-20 \mathrm{~g}$ was required to operate both manipulanda. A feeder trough was mounted on the left side of the front wall at floor level, and a Gerbrands feeder was employed to deliver $45-\mathrm{mg}$ Noyes rat pellets into it.

A $200-\mathrm{Hz}$-tone stimulus employed in training and testing was generated by a BRS AA-201 audio oscillator, amplified by a BRS A0-201 amplifier, and presented through a $20-\mathrm{cm}$ speaker mounted within an enclosure centered $20.6 \mathrm{~cm}$ above the training chamber. The tone intensity was approximately $90 \mathrm{~dB}$, measured at the lever with a Type 1565-A General Radio sound-level meter, scale C. With the exhaust fan operating, the ambient noise level was approximately $80 \mathrm{~dB}$. The tone stimulus was practically inaudible outside the attenuation chest.

The light stimulus employed in training and testing was generated by two $15-\mathrm{cm}, 25-\mathrm{W}, 120-\mathrm{V}$ bulbs, each horizontally mounted $10 \mathrm{~cm}$ from the translucent side walls. These two bulbs together produced approximately $130.2 \mathrm{~cd} / \mathrm{m}^{2}$, measured with a Honeywell Pentax $1 \% / 21^{\circ}$ photometer that was positioned $12.5 \mathrm{~cm}$ from the chamber's side wall.

A shielded 7-W, 120-V bulb operating at 3-W served as a houselight that was on continuously. The illumination it produced was too dim to activate the photometer, but it nonetheless allowed the experimenter to view the subject within the apparatus. The training chamber and its associated stimulus presentation devices were enclosed within a sound-attenuation chest described elsewhere (Weiss, 1970). Solid-state scheduling equipment was located in a room adjacent to that housing the training chambers. Constant-current shock was generated by a Lehigh Valley Electronics 1531 shocker and delivered to the grid floor, manipulandum, and front and rear walls through its associated scrambler.

\section{Procedure}

Experimental Groups FOA-VI and VI-FOA

A sequential outline of the training given the experimental groups is shown under the "Training Phase" heading in the

Table 1

Design of Experiment (Baseline Training Schedules)

\begin{tabular}{ccc}
\hline \multirow{2}{*}{$\begin{array}{c}\text { Contingency } \\
\text { Operating } \\
\text { in } \overline{\mathrm{T}}+\overline{\mathrm{L}}\end{array}$} & \multicolumn{1}{c}{ Contingency Operating in Tone and in Light } \\
\cline { 3 - 3 } VI & $\begin{array}{c}\text { Group VI-VI* } \\
\text { (Control) }\end{array}$ & FOA \\
\hline FOA & $\begin{array}{c}\text { Group VI-FOA* } \\
\text { Group FoA-VI* } \\
\text { (Experimental) }\end{array}$ & $\begin{array}{c}\text { Group FOA-FOA* } \\
\text { (Control) }\end{array}$ \\
\hline
\end{tabular}

*In designation of groups, first term specifies contingency effective in tone and in light while second indicates $\overline{\mathrm{T}}+\overrightarrow{\mathrm{L}}$ contingency. 
upper half of Table 2. Contingencies operating in tone, light, and $\bar{T}+\bar{L}$ during each phase are indicated, as well as training sessions and terminal contingency parameters for each subject.

Phase 1. The rats were initially trained to escape and subsequently to avoid trains of brief $0.4-0.6-\mathrm{sec}$ shocks by barpressing. Then an FOA contingency was instituted where responses postponed shock by $25 \mathrm{sec}$ (RS $25 \mathrm{sec)}$ while in the absence of responding shocks were delivered every $5 \mathrm{sec}$ (SS $5 \mathrm{sec}$ ). Within two to three sessions, responses emitted during a shock were scheduled to reset the shock duration timer. Training continued until response rates stabilized and the rats were avoiding at least $75 \%$ of the maximum possible shocks calculated from the RS 25 -sec contingency, i.e., they were receiving 0.6 shocks $/ \mathrm{min}$ $(60 / 25 \times .25)$ or less. During Phase 1, Group FOA-VI animals were in $2-10$-min alternating periods of tone and light while
Group VI-FOA animals were in the absence of tone and light $(\bar{T}+\bar{L})$.

Phase 2. All of Phase 2 training occurred in $\bar{T}+\overline{\mathrm{L}}$ for Group FOA-VI and in alternating periods of tone and light for Group VI-FOA. With the bar removed, the rats were trained to approach the food trough as soon as the feeder operated. When approach and ingestion were prompt, the bar was replaced and the rats were manually trained to press it, through the procedure of successive approximation, on a continuous reinforcement schedule. After approximately 50 reinforcements, this was shifted to a VI 15-sec schedule and was gradually increased over sessions. The limits of the VI schedules used were $2 \mathrm{sec}$ to 3-4 times the mean value, and the intervals were sequenced so as to keep the length of any interval independent of the preceding interval. These sessions ended when approximately 133 pellets had been

Table 2

Sequential Outline of Training Procedures for Experimental and Control Groups: Terminal Contingency Parameters, Baseline Schedules, and Training Sessions

\begin{tabular}{|c|c|c|c|c|c|c|c|c|c|}
\hline \multirow[b]{3}{*}{ Subject } & \multicolumn{4}{|c|}{ Contingency Parameters } & & & & & \\
\hline & \multirow[b]{2}{*}{ RS } & \multirow[b]{2}{*}{ VI } & \multicolumn{2}{|c|}{ Shock } & \multicolumn{5}{|c|}{ Training Phase } \\
\hline & & & $\mathrm{Sec}$ & $\mathrm{mA}$ & & 1 & 2 & 3 & 4 \\
\hline \multicolumn{10}{|c|}{ Experimental Group VI-FOA } \\
\hline & & & & & Tone & & VI & & VI-VI \\
\hline & & & & & $\underset{T}{\operatorname{Light}}$ & & VI & & VI-VI \\
\hline & & & & & $\overline{\mathrm{T}}+\overline{\mathrm{L}}$ & FOA & & FOA & FOA-FOA \\
\hline 291 & 22 & 90 & .4 & .8 & & 14 & 33 & 18 & $14-5-10$ \\
\hline 292 & 21 & 45 & .4 & 1.2 & & 33 & 16 & 3 & $22-5-15$ \\
\hline 293 & 27 & 45 & .4 & .6 & & 12 & 11 & 6 & $19-8-5$ \\
\hline 295 & 24 & 90 & .4 & .6 & & 11 & 22 & 4 & $9-6-6$ \\
\hline \multicolumn{10}{|c|}{ Experimental Group FOA-VI } \\
\hline & & & & & Tone & FOA & & FOA & FOA-FOA \\
\hline & & & & & $\underline{\text { Light }}$ & FOA & & FOA & FOA-FOA \\
\hline & & & & & $\overline{\mathrm{T}}+\overline{\mathrm{L}}$ & 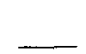 & $\underline{\text { VI }}$ & & VI-VI \\
\hline 286 & 15 & 60 & .4 & .7 & & 17 & 25 & & $28-7-9$ \\
\hline 288 & 20 & 60 & .4 & 1.2 & & 28 & 9 & 6 & $14-8-12$ \\
\hline 289 & 19 & 90 & .4 & .6 & & 12 & 22 & 4 & $22-8-42$ \\
\hline 297 & 28 & 60 & .4 & .6 & & 6 & 12 & 3 & $22-5-18$ \\
\hline \multicolumn{10}{|c|}{ Control Group VI-VI } \\
\hline & & & & & Tone & & VI & VI-VI & \\
\hline & & & & & Light & & VI & VI-VI & \\
\hline & & & & & $\overline{\mathrm{T}}+\overline{\mathrm{L}}$ & VI & & VI-VI & \\
\hline 309 & & 60 & & & & 13 & 3 & $10-5-4$ & \\
\hline 310 & & 60 & & & & 10 & 3 & $10-5-10$ & \\
\hline 311 & & 60 & & & & 9 & 3 & $10-5-11$ & \\
\hline 312 & & 45 & & & & 9 & 3 & $10-5-1$ & \\
\hline 313 & & 60 & & & & 9 & 4 & $10-5-5$ & \\
\hline \multicolumn{10}{|c|}{ Control Group FOA-FOA } \\
\hline & & & & & Tone & FOA & & FOA-FOA & \\
\hline & & & & & Light & FOA & & FOA-FOA & \\
\hline & & & & & $\overline{\mathrm{T}}+\overline{\mathrm{L}}$ & & FOA & FOA-FOA & \\
\hline 315 & 25 & & .4 & .7 & & 12 & 3 & $10-5-8$ & \\
\hline 317 & 25 & & .4 & .8 & & 10 & 3 & $10-5-4$ & \\
\hline 320 & 25 & & .4 & .6 & & 7 & 3 & $10-5-2$ & \\
\hline 321 & 25 & & .4 & .7 & & 5 & 3 & $10-5-2$ & , \\
\hline 323 & 25 & & .4 & 1.2 & & 7 & 3 & $10-5-4$ & \\
\hline
\end{tabular}

Note-Subjects 309, 310, and 311 received Phase 1 and 2 training as indicated. Subjects 312 and 313 had their VT contingencies operating in alternating periods of tone and light in Phase 1 and in $\overline{\mathrm{T}}+\overline{\mathrm{L}}$ in Phase 2. Subjects 317, 320, and 321 received Phase 1 and 2 training as indicated. Subjects 315 and 323 had their FOA contingencies operating in $\overline{\mathrm{T}}+\overline{\mathrm{L}}$ in Phase 1 and in alternating periods of tone and light in Phase 2. In Training Phase 4 for the experimental groups and Phase 3 for the control groups, the first column of entries gives sessions on the terminal training baseline prior to the preference tests. The number of preference test sessions is given in the middle column. Training sessions after the preference tests are indicated in the third column. 
earned. Phase 2 training continued for a rat until response rate was roughly comparable to that in Phase 1 . To accomplish this, VI values as well as deprivation level were manipulated.

Phase 3. For all subjects of both experimental groups, but S-286, Phase 1 conditions were reinstated and they were run for several days until their rates were stable.

Phase 4. The three-component terminal baseline multiple schedule was introduced in this phase. As in previous phases, at the commencement of an FOA component, the responseshock postponement interval was scheduled. Group FOA-VI had tone and light each assuciated with FOA, while $\bar{T}+\bar{L}$ was VI associated. The opposite stimulus-contingency combinations were scheduled for Group VI-FOA. The tone, light, and $\bar{T}+\overline{\mathrm{L}}$ components were of variable duration within sessions, the limits being 2 and $10 \mathrm{~min}$. Tone and light were each always followed by $\overline{\mathrm{T}}+\overline{\mathrm{L}}$ but either tone or light could follow $\overline{\mathrm{T}}+\overline{\mathrm{L}}$, with the restriction that neither occur more than three times in succession. Daily sessions were appreximately 4-h long. To bypass any warmup effects, discrimination performance was not measured, nor, when scheduled, did testing commence until an animal had received approximately $1 / 2 \mathrm{~h}$ of training.

The goal of Phase 4 was to establish response rates and patterning in tone and in light that were comparable to those in $\bar{T}+\bar{L}$. It was after at least 10 sessions in this phase that component preference was tested, the nondifferential response rates reestablished, and stimulus compounding tests administered.

Component preference tests. After an animal had stabilized on its terminal training baseline, with rates to tone, light, and $\mathrm{T}+\mathrm{L}$ roughly equal, this series of tests were administered. They assayed the reinforcement properties conditioned to tone and to light relative to $\bar{T}+\bar{L}$. During these sessions, the chain was introduced, and the rats could produce the schedule component programmed to occur next by pulling it. When a subject was in tone or light, pulling the chain would produce $\bar{T}+\bar{L}$. While it was in $\bar{T}+\bar{L}$, a chain pull would produce tone or light. In the absence of chain pulling, all components were programmed to be of equal duration-within the range of 2 to $5 \mathrm{~min}$ varied over sessions. All baseline contingencies were operating during these sessions. If a rat did not pull the chain, it would remain in $\bar{T}+\bar{L}$ for $50 \%$ of the session. After a chain pull, chain responses were ineffective for $5 \mathrm{sec}$.

The operant rate on the chain was extremely low when it was first introduced, keeping the subjects from contacting the component change contingency associated with it. This rate was increased by shaping the rats to chain-pull for food, followed by one session where approximately 130-150 pellets were earned by chain pulling on a VI 15 -sec contingency. During these several sessions, the bar was removed from the front wall and the opening thereby produced covered. For the experimental groups this training was given in the presence of their food associated stimuli.

After the operant level of chain pulling was thus increased, the bar was replaced, the terminal baseline schedule reinstituted, and preference tests resumed. Chain pulling now only changed components. These tests were administered until preference stabilized, showing no trend over three sessions, with a minimum of five tests scheduled. The chain was then removed and terminal baseline training continued until the nondifferential response rate criterion was satisfied. This was accomplished through manipulation of (1) deprivation level, (2) the VI contingency, (3) the response-shock (RS) postponement interval and/or (4) shock intensity.

Nondifferential response rate criterion. Satisfaction of this criterion demanded that for four successive sessions rates to tone, light, and $\bar{T}+\bar{L}$ be stable and comparable. Responding was considered stable if the standard deviation (SD) of the rates to each of these stimuli over criterion days did not exceed 1.0 or $10 \%$ of the mean, whichever was larger. Rates were considered comparable if (1) the mean of tone and light rates over these four sessions was within 0.5 response/min of the mean $\bar{T}+\bar{L}$ rate, (2) response patterning revealed by examination of cumulative records was similar in tone, light, and $\bar{T}+\bar{L}$, and (3) component change was not systematically associated with a characteristic change in response. After satisfying this criterion, a stimulus compounding test was administered.

Stimulus compounding test. Tone, light, and tone-plus-light $(T+L)$ were presented in each of 15 block-randomized replications in which $\overline{\mathrm{T}}+\overline{\mathrm{L}}$ separated these stimuli. All presentations were $1 \mathrm{~min}$ in duration, making the basic test 90 min long. All contingencies were discontinued during test replications.

If a rat stopped responding for five or more consecutive 1-min test components before Replication 10, then it was given reacquisition periods after Replications 3, 6, 9, and/or 12. A reacquisition period consisted of a 1-2-min presentation of tone and a comparable presentation of light, each followed by $\bar{T}+\bar{L}$, all with baseline contingencies operating. In order not to bias the test, care was taken to insure that no test stimulus was systematically favored by its proximity to a reinforced component.

\section{Control Groups FOA-FOA and VI-VI}

The procedural outline for the control groups is presented in the bottom half of Table 2. Group FOA-FOA's Phase 1 training was like that of Phase 1 for the experimental groups. Two subjects had $\overline{\mathrm{T}}+\overline{\mathrm{L}}$ in this phase, while three had alternating periods of tone and light. When these animals were receiving less than 0.6 shocks $/ \mathrm{min}$, they progressed to Phase 2 , where FOA was associated with the stimulus condition(s) not presented in Phase 1. Phase 1 training for Subjects 309, 310, and 311 in Group VI-VI was like the Phase 2 training received by Group VIFOA. Phase 1 training for Subjects 312 and 313 in Group VI-VI was like the Phase 2 training received by Group FOA-VI. Similar stimulus-sequence counterbalancing was used between Phases 1 and 2 for Group VI-VI as was described above for Group FOAFOA. Sessions were $2 \mathrm{~h}$ long for Group VI-VI and $4 \mathrm{~h}$ for Group FOA-FOA.

In Phase 3, the same contingency operated in tone, light, and $\overline{\mathrm{T}}+\overline{\mathrm{L}}$, FOA for Group FOA-FOA and $\mathrm{VI}$ for Group VI-VI Stimulus change was not correlated with any change in the underlying contingency for either group. After 10 Phase 3 sessions, chain pulling was established as for the experimental groups. Then five component preference test sessions were given, followed, after the nondifferential response rate criterion had been satisfied, by a stimulus compounding test. Where possible, preference test sessions in which little or no chain pulling occurred were counted as criterion sessions.

Fourteen animals had to be eliminated from the study. T'velve failed to learn to avoid adequately on the FOA contingency during Phase 1 training. Two animals, one from Group FOA-IV and another from Group VI-FOA, developed different rates to tone and to light during Phase 4 of training.

\section{RESULTS}

\section{Criterion Baseline Response Rates}

Table 3 presents criterion session response rate data for the subjects comprising the four groups. Response rates to tone, light, and $\bar{T}+\overline{\mathrm{L}}$ are in most instances almost identical. In addition, betweensession variability, represented by the SD, is usually less than $5 \%$ of the mean response rates to tone, light, or $\overline{\mathrm{T}}+\overline{\mathrm{L}}$. Inspection of the "response grain", shown in cumulative records collected during criterion sessions confirms the conclusions about response stability and comparability suggested by the rate data. The Figure 1 records generated by eight rats-two from each group-reveal no differences in response patterning between tone and light, as compared to $\overline{\mathrm{T}}+\overline{\mathrm{L}}$ components, for any subject. 
Table 3

Performance on Final Four Training Sessions (Responses Per Minute)

\begin{tabular}{|c|c|c|c|c|c|c|c|c|c|c|c|c|c|c|}
\hline & \multirow[b]{3}{*}{ Subject } & \multicolumn{6}{|c|}{$\begin{array}{l}\text { VI Contingency Operating in } \\
\text { Tone and in Light }\end{array}$} & \multirow{3}{*}{ Subject } & \multicolumn{6}{|c|}{$\begin{array}{l}\text { FOA Contingency Operating in } \\
\text { Tone and in Light }\end{array}$} \\
\hline & & \multicolumn{2}{|c|}{ Light } & \multicolumn{2}{|c|}{$\begin{array}{l}\text { Training Stimuli } \\
\text { Tone } \\
\end{array}$} & \multicolumn{2}{|c|}{$\overline{\mathrm{T}}+\overline{\mathrm{L}}$} & & \multicolumn{2}{|c|}{ Light } & \multicolumn{2}{|c|}{$\begin{array}{l}\text { Training Stimul } \\
\text { Tone }\end{array}$} & \multicolumn{2}{|c|}{$\overline{\mathrm{T}}+\overline{\mathrm{L}}$} \\
\hline & & $\mathbf{M}$ & SD & $\mathbf{M}$ & SD & $\mathbf{M}$ & SD & & M & SD & M & SD & $\mathbf{M}$ & SD \\
\hline & \multicolumn{8}{|c|}{ Group VI-VI } & \multicolumn{6}{|c|}{ Group FOA-VI } \\
\hline $\begin{array}{l}\text { VI } \\
\text { Contingency } \\
\text { Operating } \\
\text { in } \overline{\mathrm{T}}+\overline{\mathrm{L}}\end{array}$ & $\begin{array}{l}309 \\
310 \\
311 \\
312 \\
313\end{array}$ & $\begin{array}{r}9.0 \\
13.8 \\
10.4 \\
10.5 \\
17.7\end{array}$ & $\begin{array}{l}.5 \\
.7 \\
.4 \\
.1 \\
.4\end{array}$ & $\begin{array}{l}10.2 \\
14.3 \\
10.6 \\
10.7 \\
17.9\end{array}$ & $\begin{array}{r}.6 \\
.8 \\
1.3 \\
.5 \\
.5\end{array}$ & $\begin{array}{r}9.8 \\
13.5 \\
11.1 \\
10.1 \\
17.8\end{array}$ & $\begin{array}{l}.8 \\
.4 \\
.2 \\
.7 \\
1.3\end{array}$ & $\begin{array}{l}286 \\
288 \\
289 \\
297\end{array}$ & $\begin{array}{l}8.8 \\
7.0 \\
8.7 \\
6.6\end{array}$ & $\begin{array}{l}.6 \\
.8 \\
.2 \\
.2\end{array}$ & $\begin{array}{l}8.9 \\
6.5 \\
9.2 \\
6.5\end{array}$ & $\begin{array}{l}.7 \\
.7 \\
.6 \\
.7\end{array}$ & $\begin{array}{l}8.9 \\
6.6 \\
8.9 \\
6.5\end{array}$ & $\begin{array}{l}.9 \\
.3 \\
.5 \\
.8\end{array}$ \\
\hline & \multicolumn{8}{|c|}{ Group VI-FOA } & \multicolumn{6}{|c|}{ Group FOA-FOA } \\
\hline $\begin{array}{l}\text { FOA } \\
\text { Contingency } \\
\text { Operating } \\
\text { in } \bar{T}+\bar{L}\end{array}$ & $\begin{array}{l}291 \\
292 \\
293 \\
295\end{array}$ & $\begin{array}{r}8.7 \\
7.1 \\
7.7 \\
10.5\end{array}$ & $\begin{array}{l}.4 \\
.3 \\
.7 \\
.6\end{array}$ & $\begin{array}{r}8.6 \\
6.9 \\
7.7 \\
10.9\end{array}$ & $\begin{array}{r}.3 \\
.3 \\
.9 \\
1.0\end{array}$ & $\begin{array}{r}8.6 \\
7.2 \\
7.5 \\
10.4\end{array}$ & $\begin{array}{l}.1 \\
.7 \\
.4 \\
.3\end{array}$ & $\begin{array}{l}315 \\
317 \\
320 \\
321 \\
323\end{array}$ & $\begin{array}{l}6.3 \\
6.2 \\
5.8 \\
6.3 \\
5.9\end{array}$ & $\begin{array}{l}.4 \\
.8 \\
.3 \\
.4 \\
.5\end{array}$ & $\begin{array}{l}6.3 \\
6.2 \\
6.1 \\
6.1 \\
5.8\end{array}$ & $\begin{array}{l}.6 \\
.6 \\
.3 \\
.4 \\
.2\end{array}$ & $\begin{array}{l}6.0 \\
6.1 \\
6.1 \\
6.6 \\
5.8\end{array}$ & $\begin{array}{l}.2 \\
.7 \\
.1 \\
.4 \\
.2\end{array}$ \\
\hline
\end{tabular}

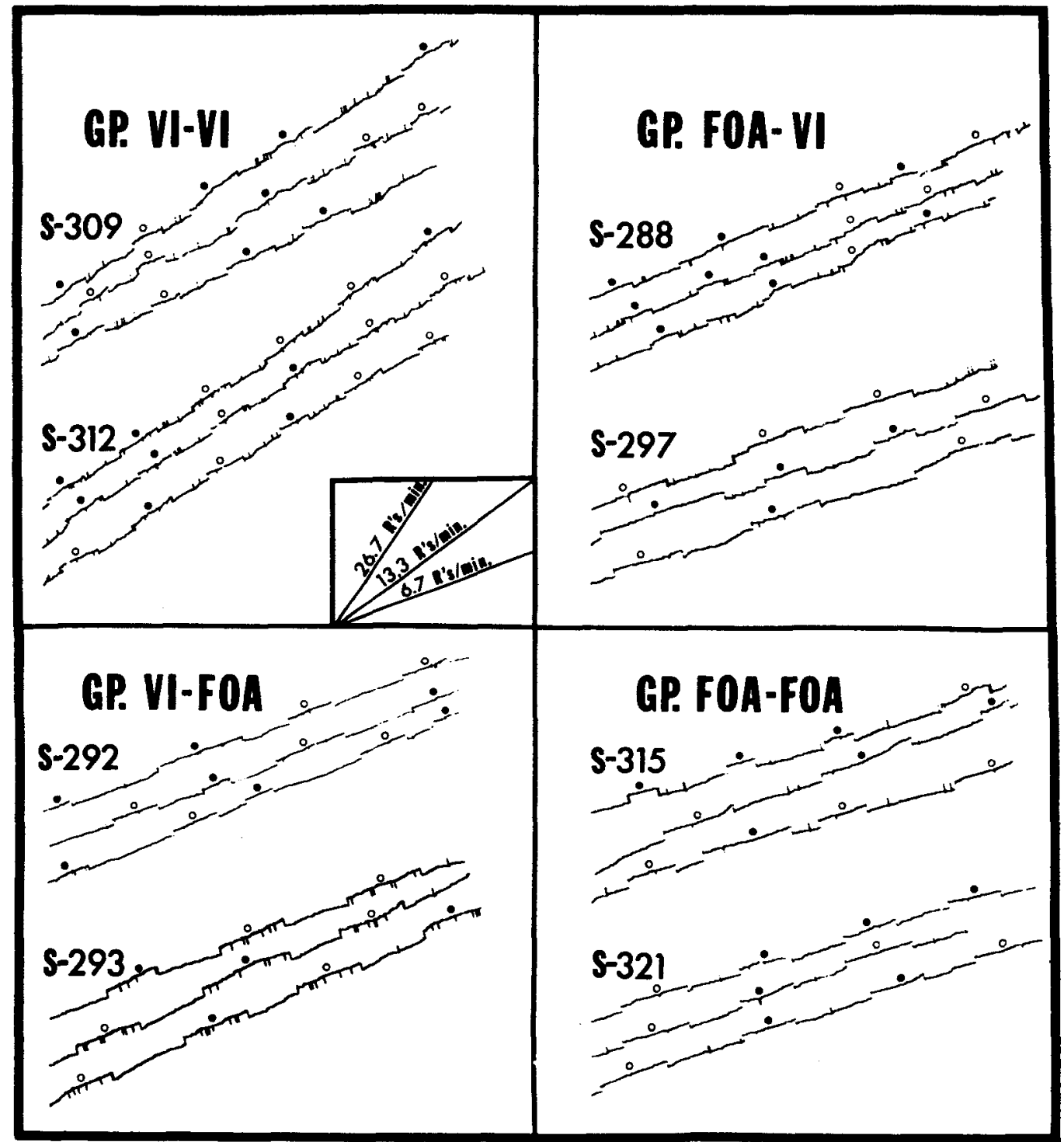

Figure 1. Cumulative records generated by two subjects from each group during a criterion training session. The response pen was in the upper register when an animal was in a tone (solid circles) or light (open circles) component. This pen was lowered during $\overline{\mathbf{T}}+\overline{\mathbf{L}}$ periods. Slash marks, whether upward or downward, indicate, as appropriate, food reinforcements or shocks. In group designation, the first term refers to the contingency operating in tone and light components, the second term to that programmed in $\bar{T}+\bar{L}$. 


\section{Component Preference Tests}

The component preference tests unmistakably reveal that, for the experimental groups, different reinforcement properties were conditioned to tone and to light as compared to $\bar{T}+\bar{L}$, even though these stimuli all controlled near identical response rates. Table 4 shows that both experimental groups choose to remain in their food-associated components for over $85 \%$ of these sessions, significantly longer than the $50 \%$ that could be expected by chance [Group FOA-Vl, $t(3)=44.5, \mathrm{p}<.001$; Group VI-FOA, $t(3)=16.7, p<.001]$. In contrast, the nondifferentially trained control groups showed absolutely no preference among stimulus components, spending $50 \%$ of these sessions in tone and in light and the other $50 \%$ in $\bar{T}+\overline{\mathrm{L}}$. The control animals stopped chain pulling after the first or second preference sessions.

\section{Stimulus Compounding Tests}

Figure 2 presents the distribution of test responses over tone, light, and $\mathrm{T}+\mathrm{L}$ conditions for the experimental and control groups in mean percentages.' The two experimental groups distributed their test responses almost identically, with Experimental Groups FOA-VI and VI-FOA emitting $43.4 \%$ and $43.9 \%$, respectively, of their responses to $T+L$. Likewise, the two control groups distributed their test responses similarly. Tone-plus-light controlled $34.1 \%$ and $34.5 \%$ of the total responses to tone, light, and $\mathrm{T}+\mathrm{L}$ for Control Groups FOA-FOA and VI-VI, respectively. Table 5 , which presents the test data from which these percentages were derived, indicates that the mean results of Figure 2 are generally representative of the behavior of the individual subjects within each group. The experimental groups emitted a significantly greater percentage of their test responses to $\mathrm{T}+\mathrm{L}$ than did the control groups $[\mathrm{t}(16)=4.62, \mathrm{p}<.001]$.
Table 4

Percent of Session in $\bar{T}+\bar{L}$ on Preference Sessions

\begin{tabular}{|c|c|c|c|c|}
\hline \multirow{3}{*}{$\begin{array}{c}\text { Contingency } \\
\text { Operating } \\
\text { in } \overline{\mathrm{T}}+\overline{\mathrm{L}} \\
\end{array}$} & \multicolumn{4}{|c|}{ Contingency Operating in Tone and in Light } \\
\hline & \multicolumn{2}{|c|}{ VI } & \multicolumn{2}{|c|}{ FOA } \\
\hline & M & SD & M & SD \\
\hline \multirow{3}{*}{ VI } & \multicolumn{2}{|c|}{ Group VI-VI } & \multicolumn{2}{|c|}{ Group FOA-VI } \\
\hline & 50.0 & .2 & 87.8 & 1.7 \\
\hline & \multicolumn{2}{|c|}{ Group VI-FOA } & \multicolumn{2}{|c|}{ Group FOA-FOA } \\
\hline FOA & 14.9 & 4.2 & 50.3 & 1.0 \\
\hline
\end{tabular}

Note-50\% $=$ no preference

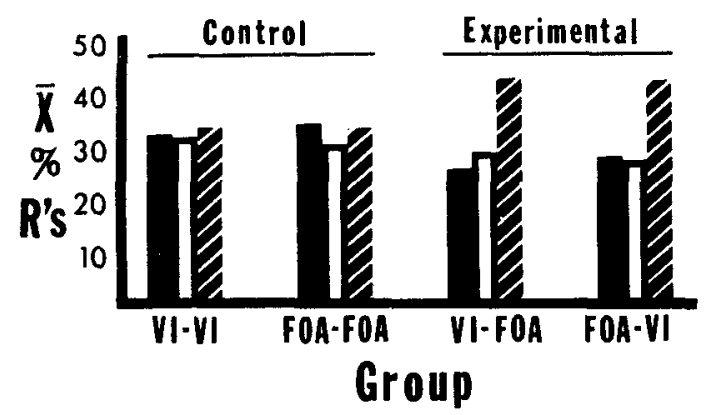

Figure 2. The mean distribution of responses to tone (solid bars), light (white bars), and tone-plus-light (striped bars) on stimulus compounding tests b! experimental and control groups. In group designation. the first term refers to the baseline contingency operating in tone and in light, and the second term (1) that programmed in $\overline{\mathbf{T}}+\overline{\mathrm{I}}$.

A mixed two-way ANOVA was employed to compare response rates to tone, light, and $\mathrm{T}+\mathrm{L}$, one for the experimental groups and another for the control groups (see Weiner, 1962, p. 298). Test stimuli were the within-subject variable and groups the between-subjects variable.

The control groups emitted responses at comparable rates to tone, light, and $T+L[F(2,16)<1]$, and the Stimulus by Groups interaction was non-

Table 5

Stimulus Compounding Test Results (Responses Per Minute)

\begin{tabular}{|c|c|c|c|c|c|c|c|c|c|c|}
\hline & \multicolumn{5}{|c|}{ VI Contingency Operating in Tone and in Light } & \multicolumn{5}{|c|}{ FOA Contingency Operating in Tone and in Light } \\
\hline & \multirow[b]{2}{*}{ Subject } & \multirow{2}{*}{\multicolumn{3}{|c|}{ Test Stimuli }} & \multirow[b]{2}{*}{$T+L$} & \multirow[b]{2}{*}{ Subject } & \multicolumn{4}{|c|}{ Test Stimuli } \\
\hline & & & & & & & $\overline{\mathrm{T}}+\overline{\mathrm{L}}$ & Tone & Light & $T+L$ \\
\hline & \multicolumn{5}{|c|}{ Group VI-VI } & \multicolumn{5}{|c|}{ Group FOA-VI } \\
\hline & 309 & 7.5 & 8.7 & 9.7 & 7.0 & 286 & 7.1 & 6.1 & 4.7 & 7.3 \\
\hline & 310 & 4.9 & 4.7 & 4.5 & 6.3 & 288 & 3.5 & 5.1 & 4.9 & 6.9 \\
\hline Contingency & 311 & 5.9 & 6.9 & 5.1 & 5.4 & 289 & 7.0 & 5.2 & 5.5 & 9.4 \\
\hline \multirow{5}{*}{$\begin{array}{l}\text { Operating } \\
\text { in } \overline{\mathrm{T}}+\overline{\mathrm{L}}\end{array}$} & 312 & 6.1 & 6.3 & 6.9 & 7.7 & 297 & 6.9 & 6.3 & 7.3 & 11.0 \\
\hline & 313 & 9.0 & 9.2 & 9.2 & 10.7 & & & & & \\
\hline & Mean & 6.7 & 7.2 & 7.1 & 7.4 & & 6.1 & 5.7 & 5.6 & 8.7 \\
\hline & \multicolumn{5}{|c|}{ Group VI-FOA } & \multicolumn{5}{|c|}{ Group FOA-FOA } \\
\hline & 291 & 4.0 & 4.7 & 6.3 & 7.4 & 315 & 3.7 & 3.7 & 3.0 & 4.2 \\
\hline FOA & 292 & 4.7 & 4.3 & 4.1 & 5.2 & 317 & 2.7 & 2.8 & 1.9 & 2.5 \\
\hline Contingency & 293 & 5.9 & 3.7 & 3.9 & 7.7 & 320 & 4.8 & 3.5 & 3.8 & 4.1 \\
\hline \multirow{3}{*}{$\begin{array}{l}\text { Operating } \\
\text { in } \overline{\mathrm{T}}+\overline{\mathrm{L}}\end{array}$} & 295 & 6.2 & 9.3 & 11.3 & 18.4 & 321 & 2.3 & 2.5 & 1.8 & 1.7 \\
\hline & & & & & & 323 & 4.0 & 3.8 & 4.3 & 4.1 \\
\hline & Mean & 5.2 & 5.5 & 6.4 & 9.7 & & 3.5 & 3.3 & 3.0 & 3.3 \\
\hline
\end{tabular}


significant $[F(2,16)<1]$. However, as is apparent from Table 5, the overall rate of Group VI-VI was significantly higher during the test than that of Group FOA-FOA $[F(1,8)=18.78, p<.005]$. This was true even though all of the animals in Group FOAFOA received reacquisition periods during the test while subjects 309,311 , and 312 of Group VI-VI maintained their responding throughout the test without reacquisition periods. The responding of Group FOA-FOA appeared to extinguish more rapidly than that of Group VI-VI.

A comparison of the response rates to tone, light, and $\mathrm{T}+\mathrm{L}$ of the experimental groups produced $\mathrm{a}$ significant $F(2,12)=12.01, p<.001$, while the groups effect $[F(1,6)<1]$ and the Stimulus by Groups interaction $[\mathrm{F}(2,12)=1.54, \mathrm{p}<.25]$ were both nonsignificant. A Newman-Keuls procedure revealed that Groups FOA-VI and VI-FOA responded at a higher rate in $\mathrm{T}+\mathrm{L}$ than in tone or light $(p<.01)$, while rates to tone and light were comparable. No subject of either experimental group even came close to requiring a reacquisition during the test. It appeared that alternating food-associated and shock-associated stimuli served to maintain a high resistance to extinction during the test.

\section{DISCUSSION}

All the subjects in Experimental Groups VI-FOA and FOA-VI responded comparably in tone, light,

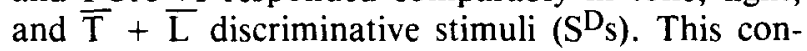
clusion is documented by the near identical mean response rates to tone, light, and $\bar{T}+\overline{\mathrm{L}}$ shown in Table 3 and by the similarity in response patterning to these three $\mathrm{S}^{\mathrm{D}_{\mathrm{S}}}$ indicated by the "grain" of the cumulative records in Figure 1. Clearly, differential $\mathrm{S}-\mathrm{R}$ associations were not formed to tone or to light. This statement applies as well to those animals comprising Control Groups VI-VI and FOA-FOA. However, on the stimulus compounding test, both experimental groups emitted significantly more responses to $\mathrm{T}+\mathrm{L}$ than to tone or light alone (additive summation) while both control groups responded at comparable rates to tone, light, and $\mathrm{T}+\mathrm{L}$. This is the first report of additive summation during stimulus compounding when the single stimuli themselves were not discriminative for an increase in response rate.

The difference in test results between the experimental and control groups must be attributed to the reinforcement manipulation distinguishing them. By having the same reinforcement schedule effective in tone or light as in $\bar{T}+\overline{\mathrm{L}}$ for the control subjectsvariable-interval (VI) food reinforcement for those in Group VI-VI and free-operant avoidance (FOA) for those in Group FOA-FOA - no differential S-S ${ }^{R}$ associations should have been conditioned to tone or light. This was confirmed by the tests indicating no preference between tone or light as compared to $\bar{T}+\bar{L}$. The data from these nondifferentia $y$ trained control groups show that when tone and light $S^{D}$ are discriminative for neither a change in response rate or reinforcement, summation will not occur to $T+L$. Nonassociative stimulus factors appear to make no contribution to the results of stimulus compounding when responding is maintained by positive or negative reinforcement.

The experimental groups had different classes of reinforcement maintain responding in tone and in light as compared to $\overline{\mathrm{T}}+\overline{\mathrm{L}}$. For Group VI-FOA, it was food in tone and in light and avoidance in $\overline{\mathrm{T}}+\overline{\mathrm{L}}$, and for Group FOA-VI it was avoidance in tone and in light and food in $\overline{\mathrm{T}}+\overline{\mathrm{L}}$. With respect to the reinforcer maintaining responding in the tone and light components, these arrangements were meant to condition an increase in reinforcement, relative to $\bar{T}+\bar{L}$, for both groups. However, VI and FOA schedule parameters were manipulated to produce equal responding in all $\mathrm{S}^{\mathrm{D}_{S}}$. Therefore, another measure was needed to identify stimulus control and determine whether S-S ${ }^{R}$ associations had been conditioned to tone and light in the experimental animals. Component preference was used to assay this reinforcement association since choice is a recognized measure of conditioned reinforcement value (Autor, 1969; Logan \& Wagner, 1965).

The experimental animals choose to remain in the VI schedule components for $85 \%-90 \%$ of their preference test sessions, with almost all responses that advanced components from FOA to VI occurring prior to shock. This indicates that reinforcement associations had been conditioned to the $S^{D}$ even though different $S-R$ associations were not, a situation rarely observed with multiple schedules. The compounding test results of the experimental animals, taken together with that of the controls, proves that $\mathrm{S}-\mathrm{S}^{\mathrm{R}}$ associations to tone and light are alone adequate to produce free-operant summation to $\mathrm{T}+\mathrm{L}$.

That $S-S^{R}$ associations alone are sufficient for summation should be considered in the context of previous research demonstrating that differential S-R associations to tone and to light were alone also sufficient for summation (Weiss, 1971; Weiss \& Van Ost, 1974). A recently completed series of studies suggested an algebraic combination principle for associations that reconciles these two findings. Weiss (1971) and Weiss and Van Ost (1974) held stimulus-reinforcer associations to tone and to light constant over different baselines while $S-S^{R}$ associations were systematically varied. On three different positive reinforcement baselines, they trained rats to respond during tone and during light, and to cease responding when these stimuli were simultaneously absent (tone-off and light-out, $\bar{T}+\overline{\mathrm{L}}$ ). Thus, tone and light each became discriminative for a compar- 
able increase in response rate ( $\mathrm{S}-\mathrm{R} \uparrow$ ) for all three groups. It was the change in reinforcement probability associated with tone and light components, relative to $\bar{T}+\bar{L}$, that distinguished the groups. They received $100 \%, 50 \%$, or $0 \%$ of their food reinforcements in tone and light such that these stimuli became associated with an increase $\left(S-S^{R} \uparrow\right)$, no change $\left(S-S^{R}=\right)$, or a decrease $\left(S-S^{R} \downarrow\right)$, respectively, in reinforcement frequency relative to $\bar{T}+\bar{L}$. Finally, tone-plus-light $(T+L)$ was presented on a stimulus compounding test. When $\mathrm{T}+\mathrm{L}$ was composed of stimuli associated with $\mathrm{S}-\mathrm{R} \uparrow$ and $S-S^{R} \uparrow$, it controlled over three times the response rate of tone or light alone, reflecting powerful additive summation. When $T+L$ was composed of stimuli associated with $\mathrm{S}-\mathrm{R} \uparrow$ but no change in reinforcement $\left(\mathrm{S}-\mathrm{S}^{\mathrm{R}}=\right)$, it controlled approximately twice the response rate of tone or light alone, indicating clear, but less substantial, summation. Finally, when $\mathrm{T}+\mathrm{L}$ was composed of stimuli associated with $\mathrm{S}-\mathrm{R} \uparrow$ and $S-S^{R} \downarrow$ rate to tone, light, and $T+L$ were comparable. These findings suggest that response and reinforcement associations enhanced each other when of similar sign, both increasing, while they counteracted each other when of opposite sign, one increasing and the other decreasing.

In the experiments described above, the organism appeared to be algebraically combining the S-R and $\mathrm{S}-\mathrm{S}^{\mathrm{R}}$ associations. If that was the case, when only one type of association had been established to tone and light, $T+L$ should control summation of an attenuated magnitude as compared to the instance when $S-R$ and $S-S^{R}$ associations are operating in concert. That expectation was clearly supported by the intermediate test results of the group for whom only differential $\mathrm{S}-\mathrm{R} \uparrow$ associations had been established to tone and light $S^{D_{S}}$ and by the experimental groups of the current experiment for whom only $\mathrm{S}-\mathrm{S}^{\mathrm{R}}$ associations had been established to these

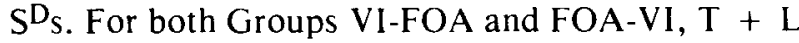
controlled 1.5 times more responding than tone or light. This postulated algebraic combination mechanism easily reconciles the fact that $\mathrm{S}-\mathrm{R}$ or $\mathrm{S}-\mathrm{S}^{\mathrm{R}}$ associations to tone and light are sufficient for summation while both associations operating in concert enhance the phenomenon. Weiss and Van Ost (1974) predicted that "If the two sources of control [response and reinforcement] are thus separable, it could be expected that when response-rates were equated over tone, light and $\bar{T}+\bar{L}$, additive summation ... should be produced during stimulus compounding by manipulating the reinforcement relations between $\overline{\mathrm{T}}+\overline{\mathrm{L}}$ and the tone and light conditions. When reinforcement rate during $\bar{T}+\bar{L}$ was lower than that in tone or light, $\mathrm{T}+\mathrm{L}$ should control additive summation" (p. 470). The results of the present experiment clearly supported that prediction, showing that $\mathrm{S}-\mathrm{S}^{\mathrm{R}}$ associations condi- tioned through differences in reinforcement between multiple schedule components can influence operant behavior.

In the studies just described, S-R $\uparrow$ associations were established to tone and to light in each of three groups while the reinforcement association to these stimuli was systematically varied, being $S-S^{R} \uparrow$, $S-S^{R}=$, and $S-S^{R} \downarrow$, respectively. If the combination rule revealed has generality, it should also apply in the situation where comparable $\mathrm{S}-\mathrm{S}^{\mathrm{R}} \uparrow$ associations were established to tone and to light in each of three groups while the response association to these stimuli was sytematically varied over groups, being $S-R \uparrow$, $S-R=$, and $S-R \downarrow$, respectively.

Emurian and Weiss (1972) trained rats on a multiple schedule where responding was maintained by FOA in tone and in light, while responding ceased in $\overline{\mathrm{T}}+\overline{\mathrm{L}}$ which was shock free. Here, where tone and light were each associated with $\mathrm{S}-\mathrm{S}^{\mathrm{R}} \uparrow$ and $\mathrm{S}-\mathrm{R} \uparrow$, $\mathrm{T}+\mathrm{L}$ controlled close to three times the rate of the single stimuli, powerful additive summation. Group FOA-VI of the present experiment had responding maintained by FOA in tone and in light, just as Emurian and Weiss, but comparable responding was maintained in $\overline{\mathrm{T}}+\overline{\mathrm{L}}$ by a Vl contingency. Here, where only differential $S-S^{R}$ associations were being added ( $\mathrm{S}-\mathrm{S}^{\mathrm{R}} \uparrow$ and $\left.\mathrm{S}-\mathrm{R}=\right), \mathrm{T}+\mathrm{L}$ controlled only 1.5 times more responding than tone or light. When responding was maintained in tone and in light by FOA at roughly one-half that in $\bar{T}+\bar{L}$, where food reinforcement was programmed, tone and light each controlled a response decrease $(S-R \downarrow)$ and an avoidance incentive increase $\left(S-S^{R} \uparrow\right)$. With these conflicting $S-S^{R} \uparrow$ and $S-R \downarrow$ associations, rates in testing to tone, light, and $\mathrm{T}+\mathrm{L}$ were comparable (Weiss, 1976, Experiment 2). ${ }^{2}$

These results of the S-R manipulation reveal a similar algebraic combination of $S-R$ and $S-S^{R}$ associations as that suggested by Weiss (1971) and Weiss and Van Ost (1974), who manipulated the $S-S^{R}$ association. The findings of this $S-S^{R}$ manipulation support the emphasis of conventional two-factor theory which postulates the "mediation" of instrumental behavior by classically conditional associa. tions. However, the results of the S-R manipulation indicate that a resultant behavior can also be manipulated by $S-R$ associations when $S-S^{R}$ associations to the compounded stimuli are kept comparable over groups.

The influence of $S-S^{R}$ associations on rate of instrumental responding has in the past been primarily revealed in transfer-of-control experiments where reinforcement associations were established off the operant baseline through an explicit classical conditioning procedure. For example, animals were initial ly trained to postpone unsignaled shocks on a freeoperant aroidance contingency (Rescorla \& L olordo, 1965; Weisman \& Limer. 1969) or io aroid in a dis- 
crete trial situation (Bull \& Overmier, 1968). A classical conditioning phase followed where a CS + signaled unavoidable shock while a CS - signaled safety. In testing, the CSs were each presented while the animals were engaged in avoidance. Avoidance rates increased above baseline during $\mathrm{CS}+$ and decreased during $\mathrm{CS}-$, supporting the two-process approach to learning originally formulated by Mowrer (1947) and Schlosberg (1937) and more recently advocated by Rescorla and Solomon (1967).

Functional similarities between the transfer-ofcontrol and stimulus-compounding paradigms have been suggested (cf. Overmier \& Schwarzkopf, 1974), and the nondifferential response baselines of the experimental groups in the present experiment encourage the comparison. In all studies under consideration from both paradigms, responding was maintained in one stimulus condition by a responsereinforcer contingency and was increased when another stimulus, that only differentially signaled a similar reinforcer, was superimposed. For example, in the Rescorla and LoLordo, (1965) and Weisman and Litner (1969) experiments, there was a higher avoidance rate to the background cues plus the CS + than to the background alone, while in the Bull and Overmier study there was a higher rate to the $S^{D}$ for avoidance plus the $C S+$ than to the $S^{D}$ alone. Similarly, in Group FOA-VI of the current experiment, there was a higher rate to two shock-associated stimuli, $T+L$, than to one, tone or light. Group VI-FOA showed similar additive effects, but controlled by positive rather than negative reinforcement associations. Thus, we have a convincing demonstration that reinforcement associations established solely through differences in reinforcement between multiple schedule components can influence behavior similarly to $S-S^{R}$ associations established independently of the operant baseline. These schedule-produced reinforcement associations are clearly involved in instrumental stimulus control, and the mechanism by which they combine with contingency-established $S-R$ associations in determining behavior deserves further exploration.

\section{REFERENCES}

Autor, S. M. The strength of conditioned reinforcers as a function of frequency and probability of reinforcement. In D. P. Hendry (Ed.), Conditioned reinforcement. Homewood: Dorsey Press, 1969. Pp. 127-162.

Bull, J. A., \& Overmer, J. B. Additive and subtractive properties of excitation and inhibition. Journal of Comparative and Physiological Psychology, 1968, 66, 511-514.

Emurian, H. H., \& Weiss, S. J. Compounding discriminative stimuli controlling free-operant avoidance. Journal of the Experimental Analysis of Behavior, 1972, 17, 249-256.
LOGAN, F. A., \& WAgNeR, A. R. Rewand and punishment. Boston: Allyn \& Bacon, 1965.

Miller, L., \& ACKLEY, R. Summation of responding maintained by fixed-interval schedules. Joumal of the Experimental A nalysis of Behavior, 1970, 13, 199-203.

MowRER, O. H. On the dual nature of learning-A re-interpretation of "conditioning" and "problem solving." Harvard Educational Review, 1947, 17, 102-148.

Overmier, J. B., \& SchwarzKopf, K. H. Summation of food and shock based responding. Leaming and Motivation, 1974, 5, $42-52$.

Rescorla, R. A. Informational variables in Pavlovian conditioning. In G. H. Bower (Ed.), The psychology of learning and motivation (Vol. 6). New York: Academic Press, 1972.

Rescorla, R. A., \& LoLordo, V. M. Pavlovian inhibition of avoidance behavior. Journal of Comparative and Physiological Psychology, 1965, 59, 406-412.

Rescorla, R. A., \& Solomon, R. L. Two-process learning theory: Relationship between Pavlovian conditioning and instrumental learning. Psychological Review, 1967, 74, 151-182.

SchlosBerg, H. The relationship between success and the laws of conditioning. Psychological Review, 1937, 44, 379-394.

Trapold, M. A., \& Overmier, J. B. The second learning process in instrumental learning. In A. H. Black \& W. F. Prokasy (Eds.), Classical conditioning II. Current theory and research. New York: Appleton-Century-Crofts, 1972. Pp. 427-451.

WEINER, B. J. Statistical principles in experimental design. New York: McGraw-Hill, 1962.

Weisman, R. G., \& Litner, J. S. Positive conditioned reinforcement of Sidman avoidance behavior in rats. Journal of Comparative and Physiological Psychology, 1969, 68, 597-603.

WEISS, S. J. Summation of response strengths instrumentally conditioned to stimuli in different sensory modalities. Journal of Experimental Psychology, 1964, 68, 151-155.

WEISS, S. J. An effective and economical sound attenuation chamber. Journal of the Experimental Analysis of Behavior, 1970, 13, 37-39.

WEISs, S. J. Discrimination training and stimulus compounding: Consideration of nonreinforcement and response differentiation consequences of $\mathrm{S}^{\Delta}$. Joumal of the Experimental Analysis of Behavior, 1971, 15, 387-402.

WEIss, S. J. Multiple schedule control of free-operant avoidance: The contribution of response rate and incentive relations between schedule components. Learning and Motivation, 1976, 7, 477.516.

WeIss, S. J., \& VAN Ost, S. L. Response discriminative and reinforcement factors in stimulus control of performance on multiple and chained schedules of reinforcement. Learning and Motivation, 1974, 5, 459-472.

Wolf, M. M. Some effects of combined $\mathbf{S D}_{\mathbf{S}}$. Journal of the Experimental Analysis of Behavior, 1963, 6, 343-347.

\section{NOTES}

1. To calculate these percentages, a subject's tone, light, and $T+L$ test response rates were each divided by the total of its rates to these conditions, and then multiplied by 100 . The percentage to each stimulus was averaged over subjects within groups to generate Figure 2.

2. A post hoc ANOVA comparing the percentages of test responses emitted to $T+L$ by these groups produced an $F(2,7)$ $=81.80, p<.001$, with each group being significantly different from the others.

(Received for publication September 23, 1976; revision accepted August 2, 1977.) 